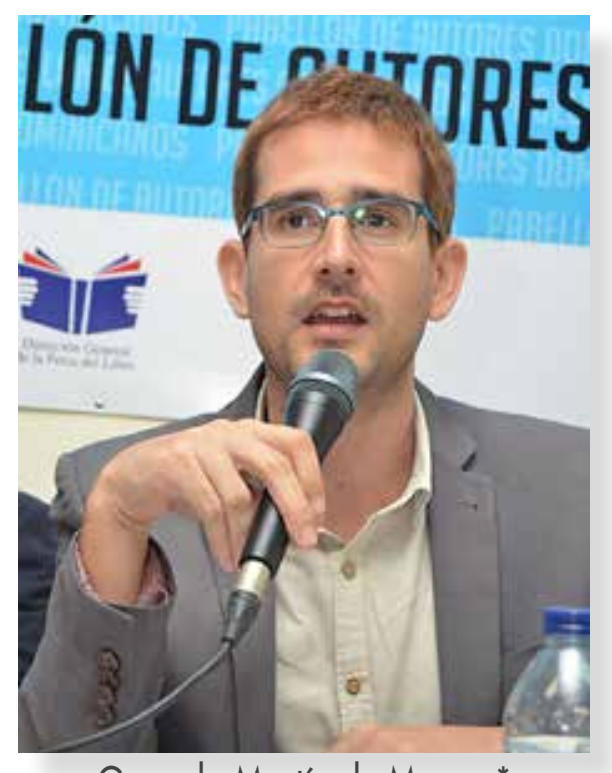

Gonzalo Martín de Marcos*

\section{Complejidad y dialogismo en los Estudios Generales: Mijail Bajtín y Edgar Morin}

\section{Complexity and Dialogism in General Education: Mikhail Bakhtin and Edgar Morin}

Recibido:31-07-17

Aprobado: 30-08-17

\title{
Resumen
}

La estructura del currículo de Estudios Generales no debería ser una simple acumulación. Las áreas pueden relacionarse mediante la complejidad dialógica, un concepto que reúne el dialigismo de Mijaíl Bajtín y la complejidad y su principio dialógico de Edgar Morin. La complejidad dialógica permite cohesionar un conjunto multidisciplinar sin reducir ningún elemento. Para ilustrarlo, se usa el ejemplo de la Historia de la Literatura.

\section{Abstract}

The structure of the curriculum of General Education should not be a mere accumulation. Areas can be related through dialogic complexity, a concept that brings together Bakhtin's dialogism and Edgar Morin's dialogical principle. Dialogic complexity allows the cohesion of a multidisciplinary set without reducing any element. To show it, the History of Literature is used as an example.

\section{Palabras clave}

Dialogismo; complejidad; Bajtín; Morin; Estudios Generales

\section{Keywords}

Dialogism; complexity; Bakhtin; Morin; General Education

\footnotetext{
*Gonzalo Martín de Marcos: Doctor en Literatura española en Arizona State University (Estados Unidos). Doctor en Filología Hispánica en la Universidad de Valladolid (España). Investigador sobre Literatura española contemporánea, Teoría de la Argumentación, Estudios de Terrorismo y Estudios Generales. Profesor a tiempo Completo del Departamento de Español y del Doctorado en Estudios del Español, en la Pontifica Universidad Madre y Maestra (PUCMM). Director del Departamento de Estudios Generales en el Campus Santo Tomás de Aquino de la PUCMM. Para contactar al autor: gonzalomartin@pucmm. edu.do
} 


\section{Introducción}

Muchas son las concepciones de Estudios Generales, desde que en el siglo XX se recuperara la raíz de las primeras universidades europeas, en la Edad Media. Tanto José Ortega y Gasset como Robert Maynard Hutchins se propusieron volver a aquello para combatir males comunes: hiperespecialización, acriticismo, trivialización de la cultura, etc. Aquí se entienden los Estudios Generales como una fase curricular compuesta por estudios principalmente humanísticos (Filosofía, Literatura, Historia, Arte), aunque no solo (pues la ciencia no procedimental también se incluye), y caracterizada por la generalidad. Esto significa que se provee una educación de validez universal (en todo tiempo, lugar y circunstancia) y que no es nunca especializada. Los Estudios Generales de la PUCMM se basan en dos principios: el humanismo y las relaciones interdisciplinares. El primero determina que no son los contenidos la sustancia de los cursos, sino la relación del ser humano con los conocimientos. El segundo dota de una estructura coherente a los cursos: todas las materias se relacionan entre sí; no hay Literatura pura, ni Ciencia Ambiental pura.

Este trabajo aborda la fusión de puntos cruciales de dos autores clásicos, con el fin de intentar dotar de una naturaleza disciplinar intrínseca a los currículos de Estudios Generales. Sucede que la interdisciplinariedad que los caracteriza se sustancia en una sucesión de disciplinas adjuntas. El desafío es acercarse a un corpus conceptual realmente común que permita llevar los meros contactos entre las disciplinas a una imbricación más trabada.

Es posible concebir los Estudios Generales como una macro-disciplina, cuya estructura sea la heterogeneidad coherente y cuya perspectiva sea un humanismo autocrítico. ${ }^{1}$ Esta armazón no debe ser entendida como reducción ni como yuxtaposición de disciplinas elementales, sino como unidad compleja (unitas multiplex), resultado distinto al del holismo, que es una unidad en que desaparecen sus constituyentes. Tal estructura debe regirse por dos conceptos interdependientes, la complejidad de Edgar Morin y el dialogismo de Mijail Bajtín. Ambos se alejan del monismo que reduce lo múltiple a lo uno; ambos, también, pese a lo que pueda parecer, se alejan del relativismo absolutista (pemítaseme el oxímoron): del primero porque hace desaparecer la disparidad en un proceso de fusión de contrarios; del segundo porque, desde sus enfoques más irredentos, niega el mismo diálogo.

La complejidad dialógica o el dialogismo de la complejidad-composición del dialogismo de Bajtín en la atmósfera de la complejidad de Morin-nos permite pensar en los Estudios Generales como un conjunto disciplinar cuya coherencia está determinada por la interrelación de elementos sin que estos lleguen nunca a perder su singularidad. La complejidad dialógica ha de permear toda la filosofía de los Estudios Generales: las relaciones disciplinares, las relaciones intradisciplinares o la relación docente-discente. La complejidad dialógica no es holística, porque en la realidad total resultante no desaparecen las partes.

\section{La complejidad de Edgar Morin}

El pensamiento complejo que postula Edgar Morin constituye una base crucial para los Estudios Generales de la era contemporánea. ${ }^{2}$ Podría pensarse, en un principio, que la complejidad coincide con el paradigma de la posmodernidad. Gran parte de los rasgos de ese movimiento-irracionalismo, relativismo, desacralización, trivialización, etc.—son una reacción contra el paradigma de la modernidad. Pero la complejidad, a mi juicio, aunque nace en este caldo, no abjura de sus contrarios: no rechaza lo cierto, sino que lo enfrenta con lo incierto; no niega lo único, sino que lo engasta en lo múltiple; no abjura del orden, sino que lo expone al desorden (Morin, 1982) no descree de la razón, sino que considera que ha de complementarla la sinrazón; ${ }^{3}$ no disuelve el objeto, sino que subraya "la gran paradoja: el sujeto y el objeto son indisociables" (Morin, 2011, p. 67).

La complejidad es un paradigma; es decir, un modelo de conocimiento. Morin postula tres principios que

\footnotetext{
${ }^{1}$ Véase Martín de Marcos (2016). Entiendo el humanismo autocrítico como una versión crítica con algunos principios del humanismo renacentista, en especial en lo que se refiere a la razón y a la idea del hombre como medida de todas las cosas.

${ }^{2}$ Esto no significa que sea el único autor que ha tratado el asunto. Véase, por su importancia, el magnífico trabajo de Rolando García, Sistemas complejos, donde estudia no sólo la complejidad, sino la relación de esta como la interdisciplina.

3 “¿La razón? ¡Yo me considero racional, pero parto de la idea de que la razón es evolutiva y que lleva en sí misma a su peor enemigo" (Morin, 2011, p. 162). Veáse también su juicio a la razón Ciencia y conciencia (1982).
} 
lo caracterizan. El primero es el principio dialógico, "que permite mantener la dualidad en el seno de la unidad" (2011, p. 106). El segundo es la recursividad organizacional, para cuya explicación emplea el autor la imagen del remolino, un hecho al mismo tiempo productor y producido; en sus palabras: "Un proceso recursivo es aquel en el cual los productos y los efectos son, al mismo tiempo, causas y productores de aquello que los produce" (Morin, 2011, p. 106). Y el tercero es el principio hologramático, por el cual el todo está en las partes y las partes están en el todo; ejemplos de ellos son los fractales, cuyas partes más pequeñas se reproducen en las más grandes; o las células, cuya información genética explica, a otra escala, el cuerpo entero; o la familia, que es una forma social de organización semejante a la comunidad (Morin, 2011). Cualquiera de estos principios caracteriza a la complejidad como un sistema abierto, proteico, en constante adaptación y acomodación, que se opone al paradigma de la simplicidad, según el cual se aplican a la realidad procesos de reducción y abstracción que tratan de hacerla comprensible mediante una simplificación que la fije, que la inmovilice.

\section{El dialogismo de Mijail Bajtin}

El dialogismo es también el principio axial del pensamiento de Mijail Bajtín. El teórico ruso es un pensador insoslayable para cualquier estudioso de la Literatura, la Lingüística, la Filosofía, la Cultura. El pensamiento de Bajtín es, en sí mismo, un emblema de la transdisciplinariedad, porque de su formación multidisciplinar y autodidacta salieron conceptos omnicomprensivos, el más importante de los cuales es el dialogismo.

El dialogismo se origina en el estudio de la poética de Fiodor Dostoyevski. Esto no significa que se circunscriba a la ciencia literaria, dentro de la que tiene un papel fundamental, sino que las novelas del escritor ruso son una base a partir de la cual reflexionar sobre el lenguaje, la cultura o la ética. En otras palabras, Bajtín no es solo un pensador sobre la Literatura sino, notablemente, un pensador desde la Literatura.

Entiéndase el dialogismo como una relación irreductible e insoluble entre dos elementos. Una relación entre dos extremos que no se absorberán ni subsumirán nunca uno en el otro. A diferencia del pensamiento monológico del idealismo alemán-que Bajtín conocía bien-, el dialogismo cree en un mundo de contrarios, en un mundo de distintos, en un mundo de complementarios. Frente a la dialéctica hegeliana, que reduce dos contrarios a un tercero que los sintetiza (tesis-antítesissíntesis), el dialogismo se queda en la misma tensión constante que caracteriza a la complejidad. Una tensión en la que se confrontarán, sin fin y entre sí, aquellos contrarios, esos distintos, estos complementarios.

Dado que el dialogismo parte de los Estudios Literarios se comprenderá bien a partir de la literatura. En una novela caracterizada por el dialogismo el narrador no impone su autoridad sobre las voces de los personajes, sino que estos conservan su independencia. Para Bajtín (2003), la realización plena del dialogismo es la novela polifónica de Fiodor Dostoyevski. Los personajes de Dostoyevski-dice Bajtín (2003ª)—"no son esclavos carentes de voz propia (...), sino personas libres, capaces de enfrentarse con su creador, de no estar de acuerdo con él y hasta de oponérsele" ( $p .14)$. Es preciso insistir en que Bajtín (2003 $)$ es un estudioso de la literatura, cuyas ideas alcanzan un vuelo trans-literario.

Es que las relaciones dialógicas representan un fenómeno mucho más extenso que las relaciones entre las réplicas de un diálogo estructuralmente expresado, son un fenómeno casi universal que penetra todo el discurso humano y todos los nexos y manifestaciones de la vida humana en general, todo aquello que posee sentido y significado (p. 67).

Por eso, parece legítimo extrapolar el dialogismo a los dominios de la ética, en que el otro, que no soy yo, no se me someterá. Dice Bajtín (2003ª): "En cada novela se representa una contraposición de muchas conciencias no neutralizadas dialécticamente, no fundidas en la unidad del espíritu" (p. 45). Es aquí inevitable la mención de otro pensador, Emmanuel Lévinas (1995), para quien, en el pensamiento occidental, la hegemonía de la ontología ha tenido consecuencias para la relación entre el Mismo y el Otro: "Para la tradición filosófica, los conflictos entre el Mismo y lo Otro se resuelven por la teoría en la que lo Otro se reduce al Mismo" (p. 71). El pensamiento de Lévinas es sobre todo una rehabilitación del Otro, que es totalmente otro, poseedor de una libertad inalienable, tal como entiende Bajtín los personajes de las novelas de Dostoyevski. El dialogismo de Bajtín coincide con la alteridad de Lévinas (1995) en evitar que el Mismo prive de alteridad al Otro (p. 62), para que entre los dos se preserve una sociedad de igualdad en la diferencia, una relación ética, terrestre (democrática). El dialogismo de Bajtín (2003a) es, así, una postura ética que asume la diferencia, y que, aunque no lo diga expresamente, nutre ideológicamente la democracia liberal-burguesa (Sartori, 2003), que no masifica ni 
subsume a los individuos, sino que salvaguarda las individualidades.

El dialogismo permea la Literatura hasta sus cimientos, esto es, la lengua. Es lo que Bajtín (2003 $)$ llama la palabra dialógica, entendida esta palabra como metonimia del lenguaje verbal humano: "[e]n el término palabra entendemos la lengua en su plenitud, completa y viva, y no hablamos de la lengua como objeto específico de la lingüística" (p. 264). Para Bajtín (1989), el diálogo externo, formalmente estructurado, se reproduce en una escala más o menos implícita en el interior de la palabra misma. Es más, cada palabra proferida-en el contexto real, en un enunciadose dirige a otra palabra respuesta, a la que tiene en consideración (p. 97). Siempre entendida la lengua en su vida social ( $p .77$ ), la palabra "se forma en una atmósfera de lo que se ha dicho anteriormente, la palabra viene determinada, a su vez, por lo que todavía no se ha dicho" (p. 97). La palabra condensa, por tanto, el pasado y el futuro, mi yo y el yo de los otros. Cuando yo empleo la palabra esclavo, por ejemplo, estoy recogiendo toda la tradición cultural que-desde el Imperio romano-estigmatizaba con tal condición a los eslavos, de donde procede etimológicamente. Cuando un niño encabeza sus frases con "eso no se hace porque..." está reproduciendo, sin citarlas, las voces de aquellos adultos que tratan de inculcarle un superego, una estructura moral. Pues bien, Bajtín (2003ª), pese a la seguridad de su teoría, descreía de la posibilidad de que la Lingüística como disciplina se ocupara de este asunto, pero la llegada de la Pragmática en los años cuarenta y cincuenta abrió una vía para su realización. Olwald Ducrot elaboró en los ochenta una adaptación lingüística del dialogismo de Bajtín. La "Teoría polifónica de la enunciación" sistematiza la pluralidad de voces en el diálogo tal como se reflejan en un discurso que no tiene por qué tratarse de un diálogo estructurado. De forma paralela a Bajtín, Ducrot llevó el dialogismo al monologismo lingüístico. (Ducrot, 1986).

El dialogismo de Bajtín (2003º, como decía, es un concepto omnicomprensivo que explica también las relaciones en la cultura. En particular, lo que Bajtín entiende por carnavalización cultural. ${ }^{4}$ Para el autor, la evolución de la cultura se explica mediante una dinámica tradición-innovación. En momentos clave de la historia-Renacimiento, Modernismo-la literatura culta ha sido carnavalizada. Es este un proceso por el cual el carnaval ha ejercido una influencia transgresora: "Llamaremos carnavalización literaria a esta transposición del carnaval al lenguaje de la Literatura" $\left(2003^{a}\right.$, p. 179). Mediante este proceso, la literatura cómico-seria introdujo en la Literatura ortodoxa el relativismo de la verdad, la inversión de las jerarquías, la inversión de los sexos, la excentricidad, la profanación; es decir, los rasgos sincréticos de tal fenómeno social. Este mundo de la disparidad es, esencialmente, un mundo dialógico. Un ejemplo, entre tantísimos de la literatura, son dos autores del seiscientos, Shakespeare y Cervantes, en cuyas obras (literatura carnavalesca), las mujeres se visten de hombres para intervenir en la vida de un modo que la rectitud social no les habría permitido, pero que la desviación carnavalesca permite y promueve.

\section{Un ejemplo dialógico para la complejidad}

Apuntaba en la introducción que la complejidad dialógica es una concepción abarcadora, que funciona como una cosmovisión, como una herramienta de pensamiento y como un método para la organización de los Estudios Generales. En este sentido, puede organizar-por usar una analogía estructuralista-las relaciones sintagmáticas y las relaciones paradigmáticas. Es decir, las relaciones dentro de una misma disciplina, tanto como las relaciones entre disciplinas equiparables. Ya decía Bajtín (2003a) que el dialogismo permea desde las relaciones interpersonales más complejas hasta la estructura interna de una simple palabra, siempre que la entendamos en un contexto vivo.

Pues bien, quiero poner un ejemplo del dialogismo como principio explicativo de la Literatura. La Historia de la Literatura está recorrida por una basculación entre dos extremos que siempre han pretendido anularse entre sí. A la Edad Media le sucedió el Renacimiento. La literatura medieval es libre y dogmática, pagana y religiosa, provocadora y sumisa; la literatura del Renacimiento, en su fase idealista, es un modelo de perfección retórico, uniforme, es imitativa, serena, equilibrada. Al Renacimiento le siguió el Barroco; el Barroco reaccionó contra aquella serenidad y se tornó desaforado, provocador de nuevo, irreverente, excesivo. Con el Neoclasicismo quiso regresarse a la serenidad, a la luz equilibrada de la razón grecolatina, que ya había practicado el Renacimiento. Después, el Romanticismo reaccionó contra tanta medición serena y estalló en emociones, rebeldías. Una nueva época objetivista llegó con el Realismo, una estética que

\footnotetext{
${ }^{4}$ Apuntado en Problemas de la poética de Dostoyevsky, este asunto lo desarrolla en su estudio sobre Rabaleis (2003 $)$. 
abjuraba del individualismo pasional del Romanticismo y que abogaba por una literatura científica, mimética, analítica.

Ya estamos a comienzos del Siglo XX y el balanceo se acelera. Los primeros movimientos del siglo son irracionalistas y espiritualistas, tendencias repudiadas por el positivismo realista. Tras las guerras mundiales, se vio el esteticismo de aquellos modernismos (parnasianismo, decadentismo, simbolismo) como actitud egoísta. Surgió entonces la Literatura social. $Y$ tras ella, en los años sesenta, llegó una nueva revolución, una nueva reacción, que volvió a dignificar el compromiso del arte con el arte. Es preciso subrayar que se trató no del arte por el arte (aunque también), sino del arte con el arte.

En este somero repaso de la Literatura de ocho siglos puede observarse que los movimientos literarios se han sucedido según una dinámica de acción-reacción. Una dialéctica que basculaba entre una literatura educativa, mimética, reglada y una literatura hedonista, imaginativa, libre. Desde un enfoque monista, una y otra tendencia podrían fundirse en una tercera, pero la realidad es que ninguna síntesis triunfó ni triunfará. Las estéticas literarias nunca podrán explicarse mediante la dialéctica hegeliana. Es más, por naturaleza, la literatura seguirá esta basculación incesante e insoluble, ad infinitum.

¿Cómo explicar entonces tal evolución? La clave la proporcionan Edgar Morin y Mijail Bajtín; la clave está en la complejidad dialógica o el dialogismo de la complejidad. Si volvemos a los principios que caracterizaban el paradigma de la complejidad, observamos que la Literatura se desarrolla en un mundo en el que las estéticas se rigen por la recursividad: Rubén Darío crea el Modernismo hispánico pero, al mismo tiempo, el contexto social, político y estético explica a Rubén Darío; estéticas regidas, también, por el principio hologramático: un autor, en el conjunto de su obra, reproduce las contradicciones de todo su siglo, incluso una obra reproduce a escala las contradicciones de toda la obra del autor; y, finalmente, la Literatura se rige por el principio dialógico, y aquí conectemos de nuevo con Bajtín (2003a). Pues, ¿qué ocurre para que las voces de la literatura comprometida nunca acallen a las voces esteticistas o viceversa? ¿Qué, para que tal tensión se reproduzca esencialmente igual en distintos siglos? Ocurre que entre los movimientos miméticorealistas y los simbólico-fantásticos rige el principio dialógico, según el cual ninguno de los elementos se resolverá en el otro, sino que habrán de convivir, sucederse o enfrentarse en un mundo complejo en permanente tensión.

Véase, para concluir, qué aspecto tendría una disolución forzosa de tal tensión dialógica. A mediados del siglo XX, el enfrentamiento entre los comprometidos mediante la literatura y los comprometidos con la literatura era muy dura. Los primeros, con Jean Paul Sartre (1967) a la cabeza, entendían la literatura como un instrumento para comprometerse con asuntos políticos y sociales. Los segundos, siempre menos beligerantes (Levinás, 1995), se defendían diciendo que su compromiso era con la literatura. Por ejemplo, en España existía la llamada 'novela social' y la también llamada 'novela deshumanizada'.

Los autores de la novela social abordaban, mediante la literatura, asuntos como la pobreza, el autoritarismo, la falta de libertades (Gil Casado, 1973). Los segundos, aunque no dejaban de tratar estos temas, los desdibujaban tras una estética opaca que se arrogaba el primer plano (Gil Casado, 1990). Es decir, que para los primeros la literatura era un medio y para los segundos era un fin inmediato. Entiendo que los segundos, los defensores de la Literatura artística, pronunciaron un subterfugio. Entiendo que comprometerse con el arte no se halla tan lejos de las imputaciones que les hacían los comprometidos. Entiendo, sin embargo, que tal subterfugio no era necesario, y que en la tensión dialógica de unos y otros puede hallarse una verdad que no ensombrezca a ningún extremo.

\section{Recomendaciones para su aplicación}

En una clase de Literatura en Estudios Generales la complejidad dialógica puede implementarse mediante diversos recursos, dos de los cuales son ejemplares. Teresa Colomer (2006) habla de una fase en la didáctica de la Literatura, la expansión, en que los textos se ponen en conexión con otras disciplinas ( $p$. 216 y ss.). De estos textos pueden extraerse lo que se llaman "centros de interés" y ver cómo se plasman en la música, en la filosofía, en la pintura, siempre sin abocar al estudiante a una resolución que funda las dos visiones. Es decir, que no se trata de que los alumnos, por ejemplo, realicen una síntesis del amor entre lo que dice una obra literaria y una obra pictórica, porque esto violentaría la esencia irreductible de la complejidad dialógica, sino de quedarse-armonizándolas o nocon ambas visiones (unitas muliplex).

Otro recurso muy recomedable es la ekfrasis, o descripción animada (Eco, 2003, p. 110), según la cual 
los textos reproducen imágenes mediante sus recursos verbales. Es un método óptimo para los contenidos interdisciplinares. Guerrero (2008) dice que permite acercarnos a la literatura mediante la imaginación icónica. La hegemonía de la imagen sobre la palabra nos permite atraer a los alumnos a la palabra mediante los referentes visuales. Los procesos interpretativos se potencian al relacionar palabra e imagen. El resultado, con todo, dentro de los Estudios Generales caracterizados por la complejidad dialógica no puede ser, insisto, un resultado, en el sentido de un producto que reduzca la interpretación de lo literario mediante la interpretación de lo visual, sino que mantenga ambas en una tensión 'incómoda' y, por tanto, reflexiva.

\section{Conclusiones}

La forma de enseñar Literatura-que es la forma en que ha de comprendérsela-en los Estudios Generales debe regirse por tal concepto, porque realiza el principio de generalidad que les da sentido: evita la especialización y promueve la interdisciplinariedad. Los alumnos egresarán de esta fase de su formación con una visión no reductiva de las realidades, lo cual redundará en su capacidad crítica y en su riqueza cognitiva. Hablo de la forma en que se enseñan los grandes movimientos literarios, los autores y cada obra en sí, porque, si gobierna el dialogismo de la complejidad, evitaremos incurrir en simplificaciones de realidades artísticas irreducibles. Lo que se dice de la Literatura, vale asimismo para la Filosofía, la Historia, la Argumentación, el Arte, etc. Cuando salvaguardamos la realidad de las simplificaciones estamos asumiendo que las teorías no deben forzar a la realidad para que esta se adapte a ellas, sino que son aquellas, las teorías — productos abstractos, reducidos-, las que han de reformularse continuamente para explicar las cosas, en sí mismas proteicas.

\section{Referencias}

Bajtín, M. (2003a). Problemas de la poética de Dostoyevski. México: Fondo de Cultura Económica.

Bajtín, M. $\left(2003^{\mathrm{b}}\right)$. La cultura popular en la Edad Media y el Renacimiento. Madrid: Alianza.

Bajtín, M. (1989). Teoría y estética de la novela. Madrid: Taurus.

Colomer, T. (2006). Andar entre libros. Barcelona: Fondo de Cultura Económica de España.
Ducrot. O. (1986). El decir y lo dicho. Barcelona: Paidós.

Eco, U. (2003). Mouse or Rat: Translations and Negotiations. London: Weidenfeld \& Nicolson.

García, R. (2006). Sistemas complejos. Barcelona: Gedisa.

Gil Casado, P. (1973). La novela social española (19201971). Madrid: Seix-Barral.

Gil Casado, P. (1990). La novela deshumanizada española (1958-1988). Madrid: Anthropos.

Guerrero, P. (2008). Metología de investigación en Educación Literaria (el modelo Ekfrástico). Murcia: DM.

Martín de Marcos, G. (2016). “Entre la razón y la sinrazón: una zona de sombra para la transdisciplinariedad entre Literatura y Filosofía". VSeminario Internacional de Estudios Generales. INTEC-RIDEG. Viernes 12 de agosto de 2016.

Morin, E. (2011). Introducción al pensamiento complejo. Barcelona: Gedisa.

Morin, E. (1984). Ciencia con consciencia. Madrid: Anthropos.

Levinas, E. (2001). La realidad y su sombra. Realidad y mandato. Trascendencia y altura. Madrid: Trotta.

Levinás, E. (1995). Totalidad e infinito. Salamanca: Ediciones Sígueme.

Sartori, Giovanni. (2003). ¿Qué es la democracia? México: Taurus.

Sartre, J. P. (1967). ¿Qué es la literatura? Buenos Aires: Editorial Losada. 